\title{
PATIENT TRIAL EVALUATION OF A PERFORATED, PIN-LOCK PROSTHETIC LINER FOR SWEAT MANAGEMENT
}

\author{
Ana Gallego ${ }^{* 1}$, Joe McCarthy ${ }^{1}$, Michael McGrath ${ }^{1}$, Alan Kercher $^{2}$, Saeed Zahedi $^{1}$, David Moser ${ }^{1}$ \\ ${ }^{1}$ Endolite Technology Centre, Basingstoke, UK \\ ${ }^{2}$ Endolite North America, Miamisburg, OH, USA \\ * Email: ana.gallego@blatchford.co.uk
}

DOI: https://doi.org/10.33137/cpoj.v1i2.32011

\section{INTRODUCTION}

Among amputees, the most commonly reported problem affecting daily quality-of-life is excessive sweating ${ }^{1,2}$. Some studies report that as many as seven out of ten amputees are affected ${ }^{1,3}$. Compared to able-bodied people, trans-tibial amputees expend up to $40 \%$ more energy during every-day activities, which contributes to excess perspiration ${ }^{4}$. Particularly common is localised sweating on the residual limb. This could be due to the use prosthetic liners made from non-porous, cushioning materials, such as TPE Gel, Polyurethane or silicones. With these problems in mind, a type of silicone liner has been produced that contains perforations along the length and at the distal end. These perforations permit the warm air to move away from the residuum, allowing better air circulation and, if sweating does occur, the perforations allow moisture to escape. The result is drier, cooler skin and a healthier environment for the residual limb. This study reports prosthetist and patient feedback data from trials of the pin-lock version of these liners.

\section{METHODS}

A custom-made questionnaire was constructed to gather feedback about both liner design and patient outcomes during the trial. All patients transitioned from their previous prosthetic liners to perforated, pin-lock liners (Silcare Breathe Locking liner - SBL - Endolite). Of all the patients identified as suitable for the trial, 23 transtibial amputees supplied responses $(3 \times \mathrm{K} 2,14 \times \mathrm{K} 3,6 \times$ K4; $20 \mathrm{x}$ unilateral, $3 \mathrm{x}$ bilateral; 17 male, 6 female). Questionnaires were requesting at fitting, and 1, 3 and 6 months into the trial.

\section{RESULTS}

The prosthetist feedback proved largely positive for the SBL liner. At the fitting stage, $100 \%$ of patients had a problem with sweating $(n=18)$, while after 3-4 months of wearing the SBL, only $33 \%$ did $(n=12)$, some of which stated that this was only during exercise. After 6 months, the only patients that still had a problem with sweating specified that it was 'greatly reduced'. At each stage of the trial, the distal seal held sufficient vacuum for over $77-92 \%$ of respondents, while no patient reported finding this seal uncomfortable at any stage in the trial. From the patient's perspective, the self-perceived issues with sweating reduced from $89 \%$ 'yes' at fitting $(n=19)$, to exclusively 'only during exercise' or 'greatly reduced' after 3 and 6 months. When asked whether they ever had to stop using their prosthesis due to sweating, $47 \%$ stated "yes" at fitting $(\mathrm{n}=17)$, whereas after 3-4 months, no-one had this issue. I Likert scale was used to rate how much heat/sweat there was compared to their previous liners (1=much less, $4=$ same, $7=$ much more); mean responses were less than 3 at all stages of the trial.

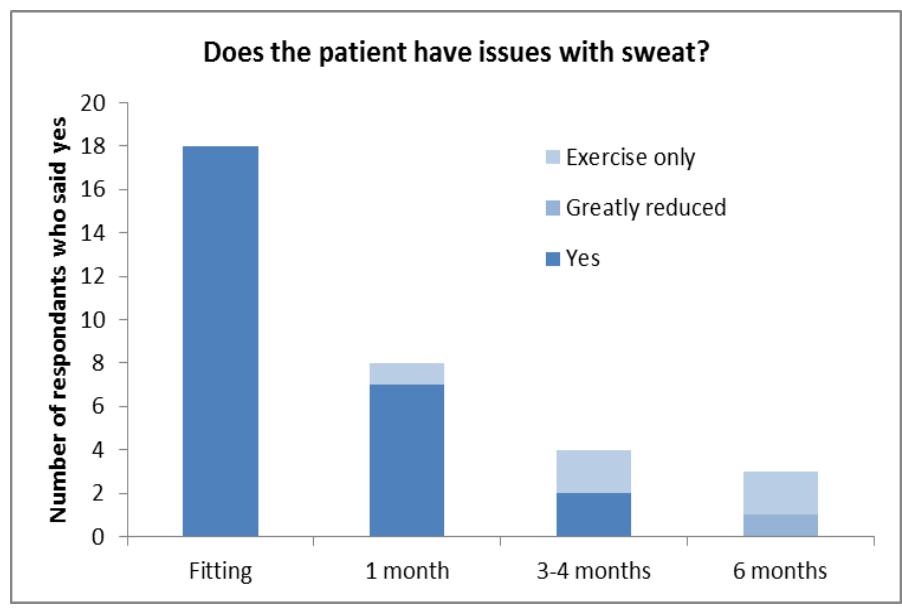

Figure 1: The prosthetist feedback from different time points during the patient trial

\section{CONCLUSION}

The findings of the SBL patient trials showed the benefits of the liner perforations. The impact of excess sweating on the patients' everyday activities was largely reduced. In particular, sweating to the extent that it stopped prosthetic limb use was completely eradicated. This will have a large impact on their independence and consequently their quality-of-life. 


\section{SIGNIFICANCE}

Appropriate sweat management can vastly improve the quality-of-life and residual limb health of amputees.

\section{REFERENCES}

1.Hagberg \& Brånemark. Consequences of non-vascular transfemoral amputation: a survey of quality of life, prosthetic use and problems. Prosthet Orthot Int. 2001;25(3):186-194. DOI: $10.1080 / 03093640108726601$

2.Meulenbelt et al. Determinants of skin problems of the stump in lower-limb amputees. Arch Phys Med Rehabil. 2009 Jan;90(1):74-81. DOI:10.1016/j.apmr.2008.07.015

3.Berke et al. Comparison of satisfaction with current prosthetic care in veterans and servicemembers from Vietnam and OIF/OEF conflicts with major traumatic limb loss. $J$
Rehabil
Res
Dev.
2010;47(4):361.

DOI:10.1682/JRRD.2009.12.0193

4.Gonzalez \& Mathews. Femoral fractures in patients with lower extremity amputations. Arch Phys Med Rehabil. 1980;61(6):276-280.

\section{DISCLOSURE}

The Authors are employees of Endolite North America or Blatchford (the parent company of Endolite North America); the manufacturer of the liner being evaluated in this study. 